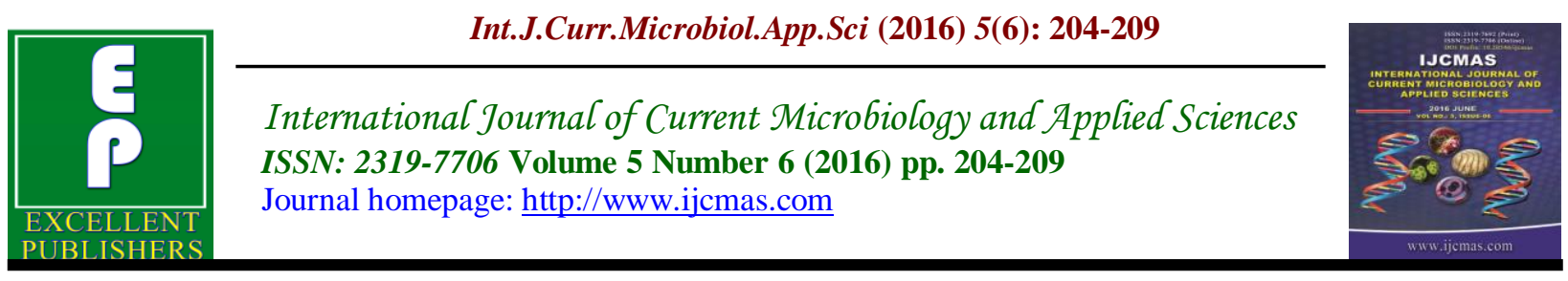

Original Research Article

http://dx.doi.org/10.20546/ijcmas.2016.506.024

\title{
Prevalence of Entamoeba histolytica and Giardia lamblia infection in a Rural Area of Haryana, India
}

\author{
Surinder Kumar ${ }^{1^{*}}$ and Varsha A. Singh ${ }^{2}$ \\ ${ }^{1}$ BPS GMC For Women Khanpur Kalan, Sonepat, India \\ ${ }^{2}$ MM Institute of Medical Sciences and Research, Mullana, Ambala, Haryana, India \\ *Corresponding author
}

\begin{abstract}
A B S T R A C T
Keywords

Entamoeba

histolytica,

Giardia lamblia,

Prevalence,

intestinal parasite

cysts, eggs,

trophozoites.

Article Info

Accepted:

12 May 2016

Available Online:

10 June 2016

An intestinal parasitic infestation is a major public health problem in India. These two important parasites of the gastrointestinal tract lead to gastroenteritis in human population. The present prospective study is carried out to check the prevalence of these two parasites in patients with gastrointestinal symptoms at MM Institute of Medical Sciences and Research Mullana, Ambala. A total of 656 stool samples of HIV negative patients with gastrointestinal symptoms from OPD and wards are included in this study. Stool specimens obtained from all participants were examined for the presence of intestinal parasite cysts, eggs, trophozoites and larvae by saline wet mount and Iodine mount. Out of 656 stool specimens Entamoeba histolytica was found in $80(12.2 \%)$ patients whereas Giardia lamblia was isolated in $6.7 \%$ cases. The Giardia lamblia was more prevalent in $<15$ years and Entamoeba histolytica was more prevalent in $>15$ years. The seasonal variation of Entamoeba histolytica and Giardia lamblia was also seen with more prevalence in hot and moist season being water borne disease $(\mathrm{p}<0.05)$.Improvement of safe drinking water supply and sanitation facilities could significantly reduce the burden of these parasitic diseases.
\end{abstract}

\section{Introduction}

An intestinal parasitic infestation is major public health problem in the world. It is estimated that 3.5 billion people are involved globally and 450 millions are suffering as a result of these infections, majority being children (WHO, 2000). The most important protozoan parasites are the Entamoeba histolytica and Giardia lamblia. Giardia lamblia (syn G. intestinalis, G.duodenalis) is one of the most common intestinal parasites in the world (WHO, 2004).
Giardiasis results in different intestinal symptoms including diarrhoea, steatorrhea, abdominal cramps, bloating, flatulence, pale greasy and malodorous stools, and weight loss; nausea or vomiting may also occur. Active infection leads to lactose intolerance which lasts for several months after clearance of the parasite (Ponce-Macotela et al., 2005). Entamoeba histolyticais another important parasite of the human gut which causesamoebiasis. It is the infection of human intestinal and extra-intestinal organs. 
The amoebic infection is considered as the third most common cause of death among parasitic diseases (Benenson AS \{ed 2011). The problem is more in tropical countries because of the humid climate, poor social economic status, improper water supply, insanitary disposal conditions and unhygienic environment (Rai et al., 2002; Rajeswari et al., 1994).The geographic variation is seen because of differing socioeconomic and environmental conditions. The problem is more in rural areas as compared to urban areas (Sayyari et al., 2005). Poly parasitism is also reported in some areas (Estevez et al., 1983; Sharma et al., 2004).

There are reports with varying isolation rates of various parasites, Entamoeba histolytica and Giardia lamblia commonly being isolated (Sayyari et al., 2005; Sharma et al., 2004) amongst protozoa. Other parasites reported are Cryptosporidium species, Balantidium coli, Trichuris trichura, Ascaris lumbricoides, Strongyloides stercoralis, Enterobius vermicularis, Hymenolepis nana (Kaur et al., 2002; Awasthi and Pande, 1997; Kang et al., 1998). Infestation rate varies in different age group (Sayyari et al., 2005; Sharma et al., 2004). Giardia lamblia is frequently reported in younger age group and Entamoeba histolyticais reported more in elderly people (Roche and Benito, 1999).The seasonal variations are very common with more infestations reported in hot and rainy season (Vargas et al., 2004).Both parasites have a low infectious dose, spread through feces and contaminated water. They have similar clinical presentations and have simple life cycles having a resistant, infectious cyst form and a fragile, disease-causing trophozoite, which are the diagnostic stages of these parasites (Tanyuksel et al., 2001). Keeping in view the above facts this study is designed to access the prevalence of Giardia lamblia and E. histolytica in the rural area surrounding Mullana.

\section{Materials and Methods}

\section{Sample Collection}

The present prospective study was conducted in the Department of Microbiology at MM. Institute of Medical Sciences and Research Mullana, Ambala. A total of 656 stool samples from HIV negative patients with gastrointestinal symptoms, irrespective of age, from OPD and wards were included in the study. A single stool sample was collected from each patient before the institutional treatment in the universal plastic container without contamination with urine, water or disinfectant and immediately transported to laboratory. Informed consent was obtained from the patient or relatives. Blood samples from the patients were also taken for knowing HIV status using standard procedures. The patient's Performa was filled regarding age, sex, place, symptoms, antibiotic treatment etc. The study was reviewed and approved by the ethical committee of the institute.

Processing of Specimens and Examination for Parasites

Stool samples were examined macroscopically for the presence of parasitic forms, mucus and blood. Microscopic examination of stool was done under low and high power in unstained preparation for typical parasitic movement and stained preparations (Iodine staining) were used for nuclear details.(Proctor EM, 1991). The negative samples were further examined by formal ether concentration technique (Petri and Singh, 1999). Half tea-spoonful of stool sample was transferred to $10 \mathrm{ml}$ of $10 \%$ formalin in shell vial and allowed to fix for 
30 minutes and then filtered through two gauge pieces into $15 \mathrm{ml}$ centrifuge tube. Normal saline was added to within $1 / 2$ inch of tube and centrifuged for 10 minutes at 500 g. Blood samples from the patients were tested by HIV Tridot method to know the HIV status of the subjects.

\section{Data Analysis}

Chi-square and paired t test and ANOVA tests were used to study significant associations or differences. For seasonal variation the study population was divided into two groups that is May to August and rest of the year.

\section{Results and Discussion}

During the study period a total of 656 stool specimens were examined. .Entamoeba histolyticawas identified in $12.2 \%$ and Giardia in $6.7 \%$ of the patients. According to the age the statistical analysis showed that there were significant relation between Age group and infectivity rate of Entamoeba histolyticaand Giardia lamblia at $(\mathrm{P} \leq 0.05)$. The Entamoeba histolytica was more prevalent in older age group with statistically significant. The Giardia lamblia was more prevalent in younger age group with statistically significant in $<15$ years of age $(\mathrm{p}<0.05)$. (Table $1 \& 2)$ The Prevalence of Entamoeba histolytica and Giardia lamblia was more in males as compared to females but it was not statistically significant ( $p>0.05)$. (Table $3 \& 4)$ The result showed that the high prevalence of Giardia lamblia and Entamoeba histolyticawas recorded in May to August, while the lower prevalence was recorded in October and November to April.(Table 5). The prevalence of Entamoeba histolytica and Giardia lamblia as single and mixed infection in stool samples is shown in Table 6.

The prevalence rates of Entamoeba histolytica and Giardia lamblia exhibit wide variation between geographic areas, different age groups and even seasonal variations are also known. Entamoeba histolyticawas more prevalent in $>15$ age group (18.5\%) as compared to children $(8.61 \%) \quad$ with significant statistical difference. Similar findings have been reported by other workers(Roche and Benito, 1999).Giardia lamblia was prevalent in younger age group and there was a statistically significant decline in prevalence of Giardia lamblia in $>15$ age group There are also reports of higher prevalence of Giardia lamblia in younger age group (Roche and Benito, 1999). The lower prevalence in adults shows that adults develop immunity after repeated infections in young age as suggested by others (Kang et al., 2003).

Table.1 Prevalence of Entamoeba histolytica and Giardia lamblia in different age groups

\begin{tabular}{|l|c|c|c|c|c|}
\hline & \multicolumn{5}{|c|}{ Number of positive samples (\%) } \\
\hline Parasites & \multicolumn{4}{|c|}{ Age group } & \multirow{2}{*}{ Total } \\
\hline & $0-5$ & $5-10$ & $10-15$ & $>15$ & \\
\hline Giardia lamblia & $18(6.5)$ & $10(10.6)$ & $8(16.6)$ & $8(3.4)$ & $44(6.7)$ \\
\hline $\begin{array}{l}\text { Entamoeba } \\
\text { histolytica }\end{array}$ & $22(7.9)$ & $10(10.6)$ & $4(8.3)$ & $44(18.5)$ & $80(12.2)$ \\
\cline { 1 - 4 } Total patients & 276 & 94 & 48 & 238 & 656 \\
\hline
\end{tabular}


Table.2 Comparison of prevalence in different age groups

\begin{tabular}{|l|c|c|c|c|c|}
\hline & Age (years ) & Positive samples & Total samples & $\chi 2$ & $\mathrm{p}$ value \\
\hline \multirow{2}{*}{ Giardia lamblia } & $<15$ & $36(8.61 \%)$ & 418 & 6.665 & $<0.01$ \\
\cline { 2 - 6 } & $>15$ & $8(3.36 \%)$ & 238 & & \\
\hline \multirow{2}{*}{$\begin{array}{l}\text { Entamoeba } \\
\text { histolytica }\end{array}$} & $<15$ & $36(8.61 \%)$ & 418 & 13.82 & $<0.001$ \\
\cline { 2 - 6 } & $>15$ & $44(18.48 \%)$ & 238 & & \\
\hline
\end{tabular}

Table.3 Prevalence of Entamoeba histolytica among males and females

\begin{tabular}{|l|l|l|l|l|}
\hline Gender & $\begin{array}{l}\text { Positive for } \\
\text { Entamoeba } \\
\text { histolytica }\end{array}$ & $\begin{array}{l}\text { Total } \\
\text { samples }\end{array}$ & $\chi^{2}$ & $p$ value \\
\hline Male & $56(12.2 \%)$ & 456 & 0.01 & $>0.05$ \\
\hline Female & $24(12.0 \%)$ & 200 & & \\
\hline
\end{tabular}

Table.4 Prevalence of Giardia lamblia among males and females

\begin{tabular}{|l|l|l|l|l|}
\hline Gender & $\begin{array}{l}\text { Positive for } \\
\text { Giardia } \\
\text { lamblia }\end{array}$ & $\begin{array}{l}\text { Total } \\
\text { samples }\end{array}$ & $\chi^{2}$ & $\mathrm{p}$ value \\
\hline Male & 36 & 456 & 3.37 & $>0.05$ \\
\hline Female & 8 & 200 & & \\
\hline
\end{tabular}

Table.5 Seasonal variation of parasite with maximum positive cases in May-August

\begin{tabular}{|l|l|l|l|}
\hline Month & $\begin{array}{l}\text { Total } \\
\text { samples }\end{array}$ & $\begin{array}{l}\text { Positive for } \\
\text { Entamoeba }\end{array}$ & $\begin{array}{l}\text { Positive for } \\
\text { Giardia }\end{array}$ \\
\hline Jan & 48 & 2 & 4 \\
\hline Feb & 20 & 0 & 2 \\
\hline Mar & 10 & 0 & 2 \\
\hline Apr & 32 & 2 & 0 \\
\hline May & 76 & 10 & 6 \\
\hline June & 56 & 16 & 6 \\
\hline July & 70 & 6 & 2 \\
\hline Aug & 142 & 18 & 12 \\
\hline Sep & 78 & 4 & 2 \\
\hline Oct & 58 & 14 & 4 \\
\hline Nov & 36 & 2 & 2 \\
\hline Dec & 30 & 6 & 2 \\
\hline Total & 656 & 80 & 44 \\
\hline
\end{tabular}


Table.6 The prevalence of Entamoeba histolytica and Giardia lamblia as single and mixed infection in stool samples

\begin{tabular}{|l|l|l|l|}
\hline Parasites & Positive & $\begin{array}{l}\text { Single } \\
\text { infection }\end{array}$ & $\begin{array}{l}\text { Mixed } \\
\text { infection(Two or } \\
\text { more organisms) }\end{array}$ \\
\hline Giardia lamblia & 44 & 32 & $12(27 \%)$ \\
\hline Entamoeba histolytica & 80 & 51 & $29(36 \%)$ \\
\hline
\end{tabular}

This may be also due to the reason that the older age group persons have better personal hygiene habits than younger children. Entamoeba histolytica and Giardia lamblia were present as mixed infection in twenty seven and thirty six percent of case(Table-6) which shows that the various parasites have their common source of infection that is contaminated water and poor sanitation. Other workers have also reported the mixed infestation in their studies attributingto similar factors (Estevez et al., 1983; Sharma et al., 2004). In the present study the prevalence of Entamoeba histolytica as well as Giardia lamblia was higher in males than in females though it was not statistically significant. Other studies have also reported the higher incidence of these parasites in males (Shenoy et al., 1998). The reason behind this may be that the males have more outdoor activities as compared to females in rural areas with the result they are more exposed to unhygienic environmental conditions as studied by other workers (Sayyari et al., 2005).

The seasonal variation was observed in present study, the finding that incidence of both Entamoeba histolytica and Giardia lamblia increased from May to august $(\mathrm{p}<0.05)$, which are hot and humid season followed by decrease in winter season. This may be due to reason that diarrhoeal diseases are more in this season due to more contamination of drinking water by various means (Natividad et al., 2008)
In conclusion, in present study we can conclude that parasitic infestation is an important cause of gastro intestinal problems in all ages with Giardia lamblia particularly in younger age group and Entamoeba histolytica in older age group. Seasonal variations show that there is need of better hygiene and safe drinking water especially in hot and humid season to prevent transmission of these infections.

\section{References}

Awasthi, S., Pande, V.K. 1997. Prevalence of malnutrition and intestinal parasites in preschool slum children in Lucknow. Indian Pediatr., 34(7): 599-605.

Benenson, A.S. (ed). 2011. Control of Communicable diseases in Man. Washington, DC.

Estevez, E.G., Levine, J.A., Warren, J. 1983. Intestinal parasites in a remote village in Nepal. J. Clin. Microbiol., 17: $160-1$.

Kang, G., Mathew, M.S., Rajan, D.P. et al. 1998. Prevalence of intestinal parasites in rural Southern Indians. Trop. Med. Int. Health, 3: 70-5.

Kaur, R., Rawat, D,. Kakkar, M., Uppal, B., Sharma, V.K. 2002. Intestinal parasites in children with diarrhoea in Delhi. South East Asian J. Trop. Med. Public Health, 33(4): 725-9.

Natividad, F.F., Buerano, C.C., Lago, C.B., Mapua, C.A., de Guzman, B.B., Seraspe, E.B., et al. 2008. 
Prevalence rates of Giardia and Cryptosporidium among diarrheic patients in the Philippines. Southeast Asian J. Trop. Med. Public Health, 39: 991-9.

Petri, W.A. Jr, Singh, U. 1999. Diagnosis and management of amoebiasis. Clin. Infect. Dis., 29: 1117-25.

Ponce-Macotela, M., G.E. Peralta-Abarca, Martínez-Gordillo, M.N. 2005. Giardia intestinalis and other zoonotic parasites:Prevalence in adult dogs from the southern part of Mexico City. Vet. Parasitol., 131: 14.20.

Proctor, E.M. 1991. Laboratory diagnosis of amoebiasis. Clin. Lab. Med., 11: 829-59.

Rai, S.K., Hirai, K., Abe, A., et al. 2002. Intestinal parasitoses among school children in a rural hilly area of the Dhading district, Nepal. Nepal Med. College J., 4: 54-8.

Rajeswari, B., Sinniah, B., Hussein, H. 1994. Socio-economic factors associated with intestinal parasites among children living in Gombak, Malaysia. Asia Pacific J. Public Health, 7: 21-5.

Roche, J., Benito, A. 1999. Prevalence of intestinal parasite infections with special reference to Entamoeba histolytica on the Island of Bioko (Equatorial Guinea). Am. J. Trop. Med. Hyg., 60(2): 257-62.

Sayyari, A.A., Imanzadeh, F., Yazdi, B., Karami, H., Yaghoobi, M. 2005.
Prevalence of intestinal parasitic infections in the Islamic Republic of Iran. East Mediterr. Health J., 11(3): 377-83.

Sharma, B.K., Rai, S.K., Rai, D.R., Choudhury, D.R. 2004. Prevalence of intestinal parasitic infestation in school children in the north-eastern part of Kathmandu valley, Nepal. Southeast Asian J. Trop. Med. Public Health, 35(3): 501-5.

Shenoy, S., Urs, S., Prabhu, G., Mathew, B., Antony, G., Bharati, B.1998. Giardiasis in the adult population of Dakshina Kannada district of south India. Trop. Doct., 28: 40-2.

Tanyuksel, M., H. Tachibana, W.A. Petri, Jr. 2001. Amebiasis, an Emerging Disease, p. 197-212. In W.M. Scheld, W.A. Craig,and J.M. Hughes (eds.), Emerging Infections. American Society for Microbiology, Washington D.C.nd Microsporidia. Parasitol., 117(Suppl), S143-S159.

Vargas, M., Gascon, J., Casals, C., et al. 2004. Etiology of diarrhoea in children less than five years of age in Ifakara, Tanzania. Am. J. Trop. Med. Hyg., 70(5): 536-9.

World Health Organization. 2000. World Health Report 2000-Conquering Suffering Enriching Humanity. Geneva: WHO, 2000. World Health Organization, 2004. Guidelines for Drinking-water quality. 3rd edition, Geneva. pp: 121-144.

\section{How to cite this article:}

Surinder Kumar and Varsha A. Singh. 2016. Prevalence of Entamoeba histolytica and Giardia lamblia infection in a Rural Area of Haryana, India. Int.J.Curr.Microbiol.App.Sci. 5(6): 204209. doi: http://dx.doi.org/10.20546/ijcmas.2016.506.024 